\title{
Sacroiliitis in children and adolescents with familial Mediterranean fever
}

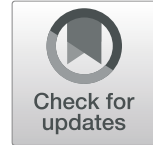

Hülya Kaçmaz ${ }^{1}$, Esin Aldemir ${ }^{2}$, Ayşe Tanatar ${ }^{3}$, Şerife Gül Karadağ ${ }^{4}$, Mustafa Çakan ${ }^{5}$, Hafize Emine Sönmez ${ }^{6}$ and Nuray Aktay Ayaz ${ }^{3 *}$

\begin{abstract}
Background: Familial Mediterranean fever (FMF) is an autoinflammatory disease characterized by recurrent episodes of fever and serositis. Sacroiliitis can be observed in some FMF patients. This study aimed to compare the demographic, clinical, and laboratory findings, and treatment in children with FMF and sacroiliitis, and children with juvenile spondyloarthropathy (JSpA).
\end{abstract}

Methods: In total, 1687 pediatric FMF patients that were followed-up between May 2010 and June 2020 were evaluated retrospectively. Among them, those with sacroilitis $(n=63)$ were included in the study and compared to patients with JSpA $(n=102)$.

Results: The study included 63 FMF patients with sacroiliitis (38 males [60.3\%] and 25 females [39.7\%]) with a mean age of $15.2 \pm 4.1$ years. Mean age at symptom onset was $7.2 \pm 5.05$ years and mean age at diagnosis was $9.74 \pm 4.67$ years. The most common mutation in the FMF patients was M694V/M694V ( $n=22)$. Patients were diagnosed with sacroiliitis with a mean of 12 months (range: 6-36 months) after the diagnosis of FMF. Among the FMF patients, 28 (44.4\%) had enthesitis, 23 (36.5\%) had heel pain, and 11 (17.4\%) had low back pain. The study also included 102 JSpA patients (90 males [88.2\%] and 12 females [11.8\%]). Mean age of patients with JSpA was $16.1 \pm 2.8$ years. As compared to $102 \mathrm{JSpA}$ patients, patients with FMF and sacroiliitis had higher acute phase reactants, whereas HLAB27 positivity rate was lower. In addition, axial involvement rate was higher in the JSpA patients.

Conclusion: Sacroiliitis is a common co-morbidity in FMF patients. The phenotypic features of these patients are different from patients with JSpA.

Keywords: Familial Mediterranean fever, Enthesitis-related arthritis, Spondyloarthropathy, Sacroiliitis, Childhood

\section{Introduction}

Familial Mediterranean fever (FMF) is an autoinflammatory disease characterized by self-limited recurrent febrile attacks and polyserositis accompanied by elevated acute phase reactants. Joint involvement is one of the most common features during the disease course and about $75 \%$ of patients have arthritis during FMF attacks. Acute recurrent monoarthritis is the most common form of musculoskeletal involvement in FMF patients, whereas about 5\% of FMF patients can develop

\footnotetext{
* Correspondence: nurayaktay@gmail.com

${ }^{3}$ Department of Pediatric Rheumatology, Istanbul University Medical School, Istanbul, Turkey

Full list of author information is available at the end of the article
}

sacroiliitis [1]. The increased frequency of sacroiliitis have been reported among FMF patients. Patients with FMF and sacroiliitis usually present with unilateral or bilateral sacroiliitis, recurrent enthesitis, and inflammatory back or neck pain [1].

Sacroiliac involvement in FMF patients can resemble spondyloarthropathy $(\mathrm{SpA})$; however, in patients with FMF and sacroiliitis, the presence of HLA-B27 or spinal involvement is unusual, whereas $\mathrm{SpA}$ is a group of seronegative arthritis type characterized by enthesitis, asymmetrical oligoarthritis of the lower extremities, axial involvement, HLA-B27 positivity, and age at onset $<16$ years. However, it is still controversial whether sacroiliitis is a part of FMF or it is related with the coexistence 
of two diseases; FMF and SpA. Revealing the differences and similarities between these two diseases may help clinicians to clarify this controversy. Therefore; the present study aimed to determine the differences between FMF patients with sacroiliitis, and patients with juvenile SpA (JSpA).

\section{Materials and methods}

The files of 1687 FMF patients and 548 JIA patients that were followed-up by the pediatric rheumatology outpatient clinic between May 2010 and June 2020 were retrospectively reviewed. Among 1687 FMF patients, those with concurrent sacroiliitis were included in the study ( $n=63$, group 1). Furthermore, among 548 JIA patients, those with JSpA were also included in the study $(n=102$, group 2). Patients having psoriasis and inflammatory bowel disease or a follow-up period of less than 6 months or missing data were excluded.

FMF was diagnosed according to pediatric FMF diagnostic criteria [2] and JSpA was diagnosed according to ILAR criteria [3].

Demographic findings (age, gender, age at diagnosis, and family history of HLA-B27-associated disease or FMF), clinical findings (fever, abdominal pain, nausea, vomiting, diarrhea, constipation, chest pain, duration of attacks, joint pain, joint swelling, muscle pain, prolonged febrile myalgia, erysipelas-like erythema, enthesitis, waist and hip pain, heel pain, and morning stiffness), and laboratory findings (complete blood count, the erythrocyte sedimentation rate [ESR], C-reactive protein [CRP], anti-nuclear antigen [ANA], HLA-B27, and MEFV gene results) were retrospectively obtained from the patients' files.

The frequency of FMF attacks, disease severity scores, use of colchicine, and colchicine resistance were evaluated. Treatments were also documented from medical files. The resistance to colchicine treatment was defined as experiencing $\geq 1$ attack per month despite receiving the maximally tolerated dose for $\geq 6$ months.

Disease severity was determined via the Pras score, which was readjusted according to the colchicine dose $[4,5]$.

MRI was performed using a $1.5 \mathrm{~T}(\mathrm{~T})$ device. Active sacroiliitis was determined via MRI according to Assessment in Spondyloarthritis International Society (ASAS) criteria. Groups 1 and 2 were compared in terms of demographic findings, clinical and laboratory findings, and treatment.

The study protocol was approved by the local ethics committee (Approval no. KAEK/2020.06.69).

\section{Statistical analysis}

Statistical analysis was performed using IBM SPSS Statistics for Windows v.21 (IBM Corp., Armonk, NY). The study variables were investigated using visual (histogram and probability plots) and analytic methods (Kolmogorov-
Smirnov and Shapiro-Wilk's tests) to determine the normality of their distribution. Descriptive analyses are presented as percentage, mean, standard deviation, median, and range, as appropriate. Categorical parameters were compared with the Chi-square test or Fisher test when appropriate. The Student's T test was used to compare normally distributed variables between the 2 groups. The Mann-Whitney $U$ test was used to compare non-normally distributed variables between the 2 groups. The level of statistical significance was set at $P<0.05$.

\section{Results}

Among 1687 FMF patients that were followed-up by the pediatric rheumatology outpatient clinic, 63 had concurrent sacroiliitis (group 1). The most common mutation was $M 694 V / M 694 V(n=22)$. Moreover, $44 \mathrm{FMF}$ patients had $\geq 1 \mathrm{M} 694 \mathrm{~V}$ mutations (Table 1). Mean duration of follow-up was $60.9 \pm 40$ months. The median colchicine dose was $3 \mathrm{mg} \mathrm{d}^{-1}$ (range: $2-3 \mathrm{mg} \mathrm{d}^{-1}$ ). The median monthly FMF attack frequency was 1 (range: $0-2$ ). The median disease severity score was 9 (range: 7-12). According to the Pras severity score, 1 (1.6\%) of the FMF patients was classified as mild, $39(61.9 \%)$ as moderate, and $23(36.5 \%)$ as severe.

The FMF patients were diagnosed with sacroiliitis with a mean of 12 months (range: 6-36 months) after being diagnosed with FMF. In all, 28 (44.4\%) of the FMF patients had enthesitis, 23 (36.5\%) had heel pain, and 11 (17.4\%) had lower back pain. Upon physical examination sacroiliac joint tenderness was detected in 26 (42\%) patients. MRI findings of sacroiliac joints were compatible with unilateral sacroiliitis in 2 of the FMF patients and bilateral sacroiliitis in 61. Among group I, 32 patients fulfilled the classification criteria for JSpA. In total, 15

Table 1 Demographical and clinical findings of patients with familial Mediterranean fever (FMF)

\begin{tabular}{ll}
\hline Findings & Number of patients \\
\hline Female/Male & $25 / 38$ \\
The mean age of patients, years & $15.1 \pm 4.1$ \\
The mean age at symptom onset, years & $7.2 \pm 5.05$ \\
The mean age at diagnosis, years & $9.7 \pm 4.6$ \\
The mean duration of disease, years & $7.4 \pm 5.3$ \\
The frequency of consanguineous marriage, $\mathrm{n}(\%)$ & $24(38.1)$ \\
The history of FMF in family & $22(34.9)$ \\
The history of FMF in siblings & $10(15.9)$ \\
Recurrent fever, $\mathrm{n}(\%)$ & $35(55.6)$ \\
Abdominal pain, $\mathrm{n}(\%)$ & $38(60.3)$ \\
Chest pain, $\mathrm{n}(\%)$ & $15(23.8)$ \\
Exertional leg pain, $\mathrm{n}(\%)$ & $22(34.9)$ \\
Erysipelas-like erythema (ELE), $\mathrm{n}(\%)$ & $19(30.2)$ \\
\hline
\end{tabular}


FMF patients received anti-TNF (adalimumab: $n=6$; etanercept: $n=9$ ) and 6 patients were treated with tocilizumab. At the time of study, all patients were inactive both clinically and laboratory means.

The study also included 102 JSpA patients (group 2), of which $90(88.2 \%)$ were male and $12(11.8 \%)$ were female. Mean age in group 2 was $16.1 \pm 2.8$ years and mean age at diagnosis of JSpA was $13.2 \pm 2.6$ years. Mean diagnostic delay was $8.3 \pm 6.1$ months. In all, $4(3.9 \%)$ of the JSpA patients had anterior uveitis. ANA test results were positive in 13 (12.7\%) patients and HLA-B27 positivity was noted in 51 (50\%). Ankylosis developed in 4 $(3,9 \%)$ patients, as follows: both ankles $(n=1)$; right ankle $(\mathrm{n}=1)$; left ankle $(n=2)$. Among the JSpA patients, 24 (23.5\%) received methotrexate and 87 (85.7\%) received salazopyrin. Biological therapy was administered to $32(27.1 \%)$ patients, as follows: etanercept: $n=23$; adalimumab: $n=9$. None of the patients in group II carried $M E F V$ mutations.

Acute phase reactants were higher (CRP; 14.4 versus 4.6, $P<0.001$ and ESR; 32 versus $16, P<0.001)$ and HLA-B27 positivity rate was lower in group 1 than in group $2(6.3 \%$ versus $50 \%, P<0.001)$. Moreover, axial involvement was not observed in group 1, but was noted in $4.9 \%$ of the patients in group $2(P=0.07)$ (Table 2$)$. The biological treatment rate in group 1 was $33.3 \%(n=$ $21)$, versus $31.3 \%(n=32)$ in group $2(P=0.79)$. Only anti-TNF drugs were used as biological agents in group 2 , whereas 15 of the patients in group 1 were treated with anti-TNF drugs and 6 with anti-interleukin 6 (tocilizumab).

\section{Discussion}

Musculoskeletal symptoms are very common in patients with FMF. Joint swelling in FMF patients usually occurs in the form of acute transient monoarthritis affecting the ankles or knees; however, some patients can also have chronic arthritis affecting the hips or small joints. The presence of $M 694 \mathrm{~V}$ mutation is associated with musculoskeletal symptoms [6]. Inflammatory back or hip pain can occur in FMF patients with sacroiliac joint involvement. Generally, such patients are negative for HLA-B27 antigen and spinal involvement is rare. The frequency of sacroiliitis is higher in Turkish and Jewish FMF patients than in those of other ethnicities [7, 8]; however, sacroiliac joint involvement is relatively rare in children. Earlier adult FMF studies noted that the frequency of sacroiliitis is 0.4$10.5 \%$ [7-10]. In addition, HLA-B27 antigen is generally negative, but positive cases are also reported, although rarely. In the present study concomitant sacroiliitis was noted in $63(3.7 \%)$ of 1687 pediatric FMF patients, of which only 4 were HLA-B27 antigen positive. Moreover, 44 of the patients had $\geq 1$ M694V mutations.

Langevitz et al. [9] evaluated 3000 adult FMF patients living in Israel and reported that the frequency of sacroiliitis was $0.4 \%$ and that 11 patients had seronegative $\mathrm{SpA}$, of which 9 were male and 2 were female with mean age at diagnosis of $32.4 \pm 7.1$ years. These 11 patients were followed-up with the diagnosis of FMF for a mean $27.4 \pm 5.1$ years. They also reported that all of these 11 patients had inflammatory back pain, and neck pain $(n=4)$, bilateral or unilateral stage $3-4$ sacroiliitis $(n=$ 7), bilateral stage 2 sacroiliitis $(n=4)$, monoarthritis $(n=$ 5), oligoarthritis $(n=6)$, enthesitis $(n=6)$, and heel pain $(n=7)$. HLA-B27 antigen was negative in all of them [9]. In the present study sacroiliitis was noted in $3.7 \%$ ( $n=$ 63) of 1687 FMF patients. Patients were diagnosed with sacroiliitis with a mean of 12 months (range 6-36 months) following diagnosis of FMF; 28 of these patients had enthesitis and 11 had lower back pain.

Table 2 Comparison of Group 1 and Group II patients

\begin{tabular}{|c|c|c|c|}
\hline Findings & Group I $(n=63)$ & Group II $(n=102)$ & $P$ value \\
\hline Gender (Female/Male), n (\%) & 25/38 (39.7)/ (60.3) & 12/90 (11.8)/ (88.2) & $<0.001$ \\
\hline Enthesitis, n (\%) & $28(44.4)$ & $36(35.2)$ & 0.18 \\
\hline Heel pain, n (\%) & $23(36.5)$ & $42(41.1)$ & 0.62 \\
\hline Low back pain, $n$ (\%) & $11(17.4)$ & $48(47.0)$ & $<0.001$ \\
\hline Ankylosis, n (\%) & $0(0)$ & $5(4.9)$ & 0.07 \\
\hline Positivity of HLA-B27, n (\%) & $4(6.3)$ & $51(50)$ & $<0.001$ \\
\hline Leukocyte count, $\left(\times 10^{3} / \mathrm{mm}^{3}\right)$ & $9800(7200-12,000)$ & $9720(6800-11,800)$ & 0.33 \\
\hline $\mathrm{CRP}^{\mathrm{a}}$ (mg/L) (normal range:0-5) & $14.4(0.8-142)$ & $4.6(0.1-137)$ & $<0.001$ \\
\hline $\operatorname{ESR}^{\mathrm{a}}(\mathrm{mm} /$ hour$)$ (normal range:0-20) & $32(20-120)$ & $16(1-112)$ & $<0.001$ \\
\hline Methotrexate, n (\%) & $19(30.1)$ & $24(23.5)$ & 0.22 \\
\hline Salazopyrin, n (\%) & $46(73.1)$ & $87(85.2)$ & 0.06 \\
\hline Biologic drugs, n (\%) & $21(33.3)$ & $32(31.3)$ & 0.79 \\
\hline
\end{tabular}

CRP C-reactive protein, ESR erythrocyte sedimentation rate, $H L A-B 27$ Human- leucocyte antigen-B27 ${ }^{\text {a }}$ These values are the values at the time of diagnosis of spondyloarthropathy 
Why sacroiliitis occurs in FMF patients remains a matter of debate; however, a family history of SpA in some patients suggests a genetic relationship. Akar et al. [11] reported an increased risk of sacroiliitis in adult patients with FMF and their families (the risk ratio is 3.3 [95\% CI: 2-5] in first-degree relatives and 2.9 [95\% CI: 1.36.4] in individuals with FMF). Of the 63 FMF patients with sacroiliitis in the present study, 22 had a family history of FMF, but none had a family history of SpA.

Sacroiliitis has also been reported in pediatric FMF patients. Sonmez et al. [12] compared 15 children diagnosed with FMF and sacroiliitis, and 30 juvenile SpA patients, observing that the FMF patients with sacroiliitis had higher inflammatory markers, whereas the frequency of enthesitis, axial involvement, and HLA-B27 antigen positivity was lower. Aydın et al. [13] analyzed 650 children with FMF and reported that 17 (2.6\%) had sacroiliitis, of which $90 \%$ carried the $M 694 \mathrm{~V}$ mutation. Özdel et al. [14] compared 18 children with FMF and sacroiliitis, and 38 children diagnosed with JSpA, noting that there was no difference between the 2 groups in HLAB27 antigen positivity, family history, clinical findings, enthesitis, or treatment. In the present study the patients with FMF and sacroiliitis had higher acute phase reactants and a lower HLA-B27 antigen positivity rate, as well as no axial involvement. In addition, there wasn't a significant difference between groups 1 and 2 in terms of the presence of enthesitis.

There is no standard treatment for FMF associated with sacroiliitis. Sonmez et al. [12] reported treating all such patients with non-steroidal anti-inflammatory drugs, and that 9 patients were treated with methotrexate, 9 with sulfasalazine, and 10 with anti-TNF (etanercept). Aydin et al. [13] reported that of 17 patients diagnosed with FMF and sacroiliitis, 14 were treated with non-steroidal anti-inflammatory drugs in addition to colchicine, 10 received sulfasalazine, and 7 received biological drugs. Özdel et al. [14]] compared 18 children with FMF and sacroiliitis, and 38 children diagnosed with JSpA, reporting that there was no difference between the 2 groups in terms of treatment. Cherqaoui et al. [15] observed that patients diagnosed with FMF and JSpA required fewer non-steroidal anti-inflammatory drugs and anti-TNF drugs than patients with other JSpA. In the present study anti-TNF drugs were given to 15 of the FMF patients with sacroiliitis (adalimumab: $n=6$; etanercept: $n=9$ ) in addition to colchicine, and 6 patients were using tocilizumab. Moreover, the biological drug use rate did not differ significantly between groups 1 and 2, but the preferred biological therapy varied. Tocilizumab failed to achieve remission in the adult patients with spondyloarthritis [16]. However, previous studies have reported successful results with tocilizumab in FMF patients $[17,18]$. In presented study, all 6 patients with FMF and sacroiliitis receiving tocilizumab achieved remission in terms of FMF and sacroilliitis. This suggests that FMF and sacroillitis has different pathogenetic mechanisms than JSpA.

The limitation of the present study is its retrospective design, whereas the large number of patients included is a strength.

\section{Conclusion}

To the best of our knowledge the present study is the largest such study to date, highlighting the association between FMF disease and sacroiliitis. These patients may show different phenotype than classical JSpA patients. Further delineation of the clinical and laboratory findings in pediatric FMF patients with sacroiliitis will facilitate easier diagnosis and prevent delays in treatment. Although clinical differences are revealed, studies on etiopathogenesis are needed to show the main differences of these two diseases.

\section{Acknowledgments \\ None.}

\section{Authors' contributions}

HK conceptualized and designed the study, drafted the initial manuscript, and had full access to all the data in the study; EA, AT, SGK, MÇ, HES and NAA designed the study, conducted the data analyses, drafted the initial manuscript, and had full access to all the data in the study. All authors reviewed and revised the manuscript and approved the final version of the manuscript.

\section{Funding}

None.

Availability of data and materials Not applicable.

\section{Declarations}

Ethics approval and consent to participate

The study protocol was approved by the local ethics committee (Approval no. KAEK/2020.06.69).

Consent for publication

All authors gave consent for publication.

\section{Competing interests}

The authors have declared no conflicts of interest.

\section{Author details}

'Department of Pediatric Rheumatology, University of Health Sciences, Kanuni Sultan Süleyman Research and Training Hospital, Istanbul, Turkey. ${ }^{2}$ Department of Pediatric Rheumatology, University of Health Sciences, Başakşehir Çam ve Sakura City Hospital, Istanbul, Turkey. ${ }^{3}$ Department of Pediatric Rheumatology, Istanbul University Medical School, Istanbul, Turkey. ${ }^{4}$ Department of Pediatric Rheumatology, Sadi Konuk Research and Training Hospital, Istanbul, Turkey. ${ }^{5}$ Department of Pediatric Rheumatology, University of Health Sciences, Zeynep Kamil Research and Training Hospital, Istanbul, Turkey. ${ }^{6}$ Department of Pediatric Rheumatology, Kocaeli University, Istanbul, Turkey. 
Received: 15 January 2021 Accepted: 20 May 2021

Published online: 05 June 2021

\section{References}

1. Younes M, Kahn MF, Meyer O. Hip involvement in patients with familial Mediterranean fever. A review of ten cases. Joint Bone Spine. 2002;69(6): 560-5. https://doi.org/10.1016/\$1297-319X(02)00452-9.

2. Yalcinkaya F, Ozen S, Ozcakar ZB, Aktay N, Cakar N, Duzova A, et al. A new set of criteria for the diagnosis of familial Mediterranean fever in childhood. Rheumatology (Oxford). 2009;48(4):395-8. https://doi.org/10.1093/rheuma tology/ken509.

3. Petty RE, Southwood TR, Manners P, Baum J, Glass DN, Goldenberg J, et al. International league of associations for rheumatology classification of juvenile idiopathic arthritis: second revision, Edmonton, 2001. J Rheumatol. 2004;31(2):390-2.

4. Ozen S, Aktay N, Lainka E, Duzova A, Bakkaloglu A, Kallinich T. Disease severity in children and adolescents with familial Mediterranean fever: a comparative study to explore environmental effects on a monogenic disease. Ann Rheum Dis. 2009;68(2):246-8. https://doi.org/10.1136/ard.2008.092031.

5. Pras E, Livneh A, Balow JE, Pras E, Kastner DL, Pras M, et al. Clinical differences between north African and Iraqi Jews with familial Mediterranean fever. Am J Med Genet. 1998;75(2):216-9. https://doi.org/10.1 002/(SICI)1096-8628(19980113)75:2<216::AID-AJMG20>3.0.CO;2-R.

6. Akkoc N, Gul A. Familial Mediterranean fever and seronegative arthritis. Curr Rheumatol Rep. 2011;13(5):388-94. https://doi.org/10.1007/s11926-011-0191-9.

7. Cefle A, Kamali S, Sayarlioglu M, Inanc M, Ocal L, Aral O, et al. A comparison of clinical findings of familial Mediterranean fever patients with and without amyloidosis. Rheumatol Int. 2005;25(6):442-6. https://doi.org/10.1007/s002 96-004-0471-z

8. Kasifoglu T, Calisir C, Cansu DU, Korkmaz C. The frequency of sacroiliitis in familial Mediterranean fever and the role of HLA-B27 and MEFV mutations in the development of sacroiliitis. Clin Rheumatol. 2009;28(1):41-6. https:// doi.org/10.1007/s10067-008-0980-3.

9. Langevitz P, Livneh A, Zemer D, Shemer J, Pras M. Seronegative spondyloarthropathy in familial Mediterranean fever. Semin Arthritis Rheum. 1997;27(2):67-72. https://doi.org/10.1016/S0049-0172(97)80007-8.

10. Tunca M, Akar S, Onen F, Ozdogan H, Kasapcopur O, Yalcinkaya F, et al. Familial Mediterranean fever (FMF) in Turkey: results of a nationwide multicenter study. Medicine (Baltimore). 2005;84:1-11.

11. Akar S, Soysal O, Balci A, Solmaz D, Gerdan V, Onen F, et al. High prevalence of spondyloarthritis and ankylosing spondylitis among familial Mediterranean fever patients and their first-degree relatives: further evidence for the connection. Arthritis Res Ther. 2013;15:R21.

12. Sonmez HE, Batu ED, Demir S, Bilginer Y, Ozen S. Comparison of patients with familial Mediterranean fever accompanied with sacroiliitis and patients with juvenile spondyloarthropathy. Clin Exp Rheumatol. 2017;108:124-7.

13. Aydin F, Ozcakar ZB, Cakar N, Celikel E, Uncu N, Celikel Acar B, et al. Sacroiliitis in children with familial Mediterranean fever. J Clin Rheumatol. 2019;25(2):69-73. https://doi.org/10.1097/RHU.0000000000000770.

14. Ozdel S, Baglan E, Cakici EK, Yazilitas F, Gur G, Celikkaya E, et al. Similarities between pediatric FMF patients with sacroiliitis and pediatric juvenile spondyloarthropathy patients with sacroiliitis: a preliminary study. Acta Clin Belg. 2020:1-6. https://doi.org/10.1080/17843286.2020.1724450.

15. Cherqaoui B, Rossi-Semerano L, Georgin-Lavialle S, Dusser P, Galeotti C Piram $M$, et al. Boundaries between familial Mediterranean fever and juvenile spondyloarthritis: analysis of three French retrospective cohorts. Joint Bone Spine. 2018;85(6):733-9. https://doi.org/10.1016/j.jbspin.2018.01. 010.

16. Sieper J, Porter-Brown B, Thompson L, Harari O, Dougados M. Assessment of short-term symptomatic efficacy of tocilizumab in ankylosing spondylitis: results of randomised, placebo-controlled trials. Ann Rheum Dis. 2014;73(1): 95-100. https://doi.org/10.1136/annrheumdis-2013-203559.

17. Kuemmerle-Deschner JB, Gautam R, George AT, Raza S, Lomax KG, Hur P. A systematic literature review of efficacy, effectiveness and safety of biologic therapies for treatment of familial Mediterranean fever. Rheumatology (Oxford). 2020:59(10):2711-24. https://doi.org/10.1093/rheumatology/keaa205.

18. Umeda M, Aramaki T, Fujikawa K, Iwamoto N, Ichinose K, Terada K, et al. Tocilizumab is effective in a familial Mediterranean fever patient complicated with histologically proven recurrent fasciitis and myositis. Int J Rheum Dis. 2017;20(11):1868-71. https://doi.org/10.1111/1756-185X.12776.

\section{Publisher's Note}

Springer Nature remains neutral with regard to jurisdictional claims in published maps and institutional affiliations.
Ready to submit your research? Choose BMC and benefit from:

- fast, convenient online submission

- thorough peer review by experienced researchers in your field

- rapid publication on acceptance

- support for research data, including large and complex data types

- gold Open Access which fosters wider collaboration and increased citations

- maximum visibility for your research: over $100 \mathrm{M}$ website views per year

At $\mathrm{BMC}$, research is always in progress.

Learn more biomedcentral.com/submissions 